\title{
PERANCANGAN ALAT UJI TARIK MORTAR MENGGUNAKAN TENAGA PENGGERAK MOTOR LISTRIK
}

\author{
Sarito $^{1}$, Muhtarom Riyadi ${ }^{2}$, Handi Sudardja ${ }^{3}$. \\ 1,2,3 Jurusan Teknik Sipil, Politeknik Negeri Jakarta (PNJ) \\ Email: 1sarito14@gmail,com, ㄹmuhtard37@gmail.com, 3handi_sudardja@yahoo.co.id
}

\begin{abstract}
Mechanic characteristics of hard mortar are: compressive strength, flexural strength, tensile strength, and adhesion power. In the meantime, at Building Material Laboratory of Civil Engineering, State Polytechnic of Jakarta, test of tensile strength and adhesion power of mortar cannot be conducted because of the absence of the test equipment.

This research aims to provide electric motor-powered equipment for tensile strength test of mortar in order to complete the equipment at Building Material Laboratory of Civil Engineering, State Polytechnic of Jakarta. The particular aim of the research is to make prototype of mortar tensile strength test equipment. In this research a prototype of motor-powered mortar tensile strength test equipment and the specimens, to test the performance of the equipment, were prepared. By examining the obstacles and shortcomings, this equipment is a development of the previous research by Muhtarom Riyadi and the team, 2015. The specimens, as the sample to test the equipment, were prepared by the ratio of one part of cement and three part of fine aggregate, with the total number of the specimens of 50 pieces.

By analyzing the result of observation in trial period, the equipment could function as it should be. The magnitude of maximum tensile strength that causes the mortar specimens to break depends on the quality, age, and tensile area of mortar, which magnitude can be observed in manometer or scale with the unit of kilogram.
\end{abstract}

Keywords: equipment, tensile, mortar, electric motor

\section{ABSTRAK}

Sifat mekanis mortar keras antara lain kuat tekan, kuat lentur, kuat tarik dan daya lekat. Sementara ini di Laboratorium bahan bangunan Jurusan Teknik Sipil Politeknik Negeri Jakarta untuk uji kuat tarik dan daya lekat mortar belum bisa dilaksanakan karena belum adanya peralatan untuk melakukan pengujian.

Penelitian ini bertujuan untuk membuat alat uji tarik mortar menggunakan tenaga penggerak motor listrik guna melengkapi peralatan yang diperlukan di Laboratorium bahan bangunan Jurusan Teknik Sipil Politeknik Negeri Jakarta. Target khusus yang ingin dicapai adalah membuat prototype alat uji tarik mortar.

Dalam penelitian ini akan dibuat prototipe alat uji tarik mortar menggunakan tenaga motor listrik dan cetakan benda ujinya, sekaligus untuk menguji kinerjanya. Alat ini merupakan pengembangan oleh peneliti yang terdahulu Muhtarom Riyadi dan anggotanya, 2015), dengan mencermati kendala dan kekurangannya maka penelitian ini merupakan penyempurnaan penelitian sebelumnya Sebagai sampelnya dibuat benda uji tarik mortar dengan perbandingan 1 bagian semen berbanding 3 bagian pasir, sedangkan jumlah benda uji dibuat sebanyak 50 buah.

Hasil pengamatan selama uji coba maka alat alat uji tarik mortar menggunakan tenaga penggerak motor listrik dapat berfungsi sebagaimana mestinya. Besarnya gaya tarik maksimum yang menjadikan benda uji tarik mortar putus tergantung dari mutu mortar, umur serta luas penampang tarik yang nilainya dapat diamatai pada manometer atau timbangan berat dengan satuan kilogram

Kata kunci : Alat, uji, tarik, mortar, motor listrik

\section{PENDAHULUAN}

Mortar ialah bahan bangunan yang terbuat dari air bahan perekat dan agregat halus. Mortar dalam konstruksi bangunan biasanya digunakan sebagai perekat antara bata merah, perekat antara bata beton, perekat antara batu dan juga sebagai plesteran.Mortar sebagai bahan bangunan biasa diukur sifat fisis dan mekanisnya, meliputi : konsistensi, perubahan panjang, water retentive,kuat tekan, kuat tarik, dan sebagainya (Tjokrodimuljo, 
2007).Kegiatan praktek di laboratorium uji bahan, khususnya untuk pengujian mortar yang telah dilakukan selama ini meliputi, uji konsistensi, kuat tekan, kuat lentur, perubahan panjang dan water retentive, sedangkan untuk uji tarik mortar dan lekatan mortar terhadap bata belum dapat dilakukan, hal ini terpaksa karena belum ada alatnya untuk melakukan pengujian. Oleh sebab itu alat uji tarik mortar ini sangat mendesak untuk diadakan agar dapat membantu dalam proses belajar mengajar di laboratorium Uji Bahan Jurusan Teknik Sipil Politeknik Negeri Jakarta.

Rancangan Alat Uji Tarik Mortar Menggunakan Tenaga Penggerak Motor Listrik merupakan kelanjutan dari peneliti terdahulu oleh Muhtarom Riyadi, 2015 dengan judul Perancangan Alat Uji Tarik Mortar. Pada alat tersebut menggunakan tenaga manusia sebagai sumber tenaga penggerak, ketika digerakkan dengan memutar engkol atau lengan pemutar menghasilkan gaya tarik yang kurang stabil sehingga perlu maka guna memperoleh putaran dan gaya tarik yang stabil digunakan tenaga penggerak motor listrik.

\section{METODA PENELITIAN}

Metode penelitian berupa Perancangan dan Pembuatan Alat Uji Tarik Mortar Menggunakan tenaga Penggerak Motor Listrik dengan tahapan-tahapan yang disajikan pada bagan alir seperti pada Gambar 2.1. dibawah ini.

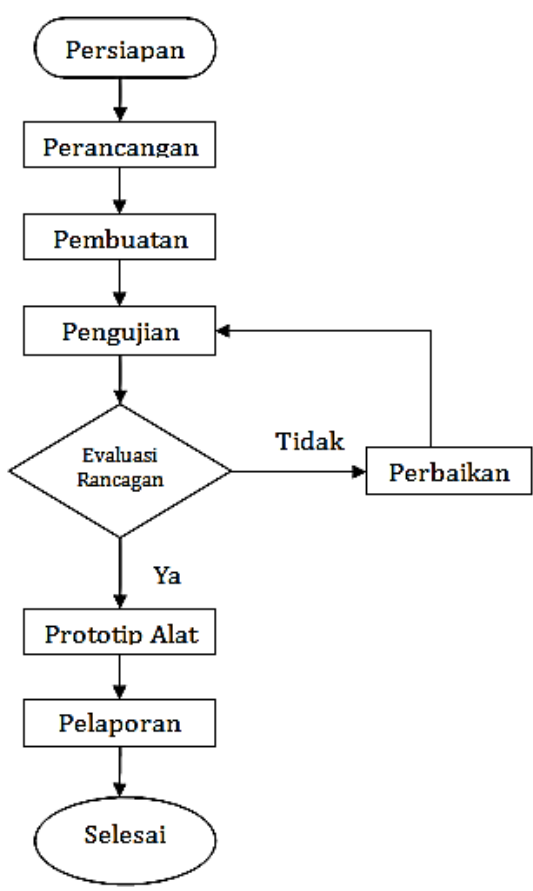

Gambar 2.1 Bagan alir penelitian

\subsection{Prinsip Kerja Alat}

Prinsip kerja alat ditunjukkan pada ilustrasi gambar 2.2.

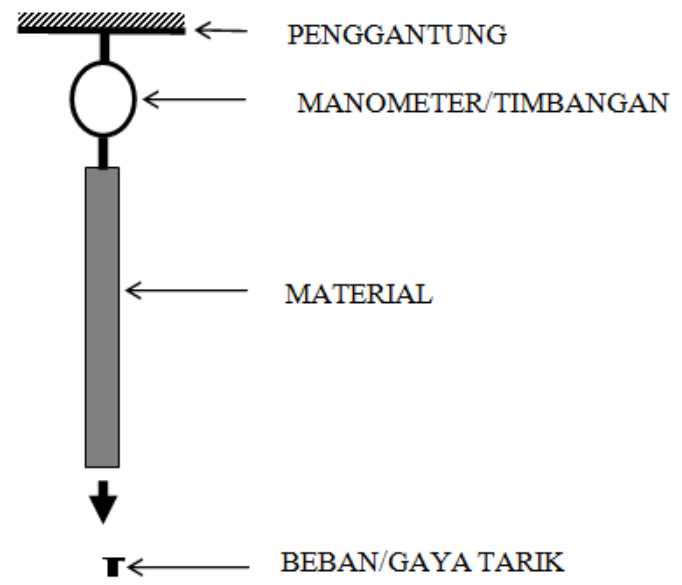

Gambar 2.2 Ilustrasi prinsip kerja alat

Keterangan

1. Material merupakan benda uji mortar yang akan dilakukan uji tariknya

2. P. merupakan beban atau gaya tarik adalah gaya yang diberikan kepada benda uji samapi putus

3. Manometer atau timbangan merupakan alat ukur yang mencerminkan besaran nilai beban atau gaya tarik yang ditopang ole mortar yang ditarik dan nilai ini sama dengan nilai $\mathrm{P}$ 
4. Penggantung merupakan dudukan manometer/timbangan agar stabil

Beban atau gaya $\mathrm{P}(\mathrm{kg})$ adalah gaya sistem penarik menggunakan motor listrik dan manometer atau timbangan merupakan alat ukur berat yang harus diperhitungkan sebelumnya agar kapasitasnya harus lebih besar dari nilai $\mathrm{P}$ swaktu benda uji putus yang juga merupakan beban maksimum. Material merupakan benda uji tarik yang mempunyai luas penampang $\mathrm{A}$ tertentu $\left(\mathrm{cm}^{2}\right)$, sehingga kuat tarik material $\frac{P}{\mathrm{~A}}\left(\frac{\mathrm{kg}}{\mathrm{cm}^{2}}\right)$

\subsection{Perancangan Alat}

Alat yang dirancang dan yang akan dibuat "Prototipe Rancangan Alat Uji Tarik Mortar Menggunakan Tenaga Penggerak Motor Listrik " dengan sistem kerja secara mekanik dan eleektrik. Rancangan ini merupakan pengembangan dari alat yang sudah dirancang oleh Muhtarom Riyadi dan anggotanya, dengan peningkatan sesuai dengan kendala/ keterbatasan dan saran yang telah tertuang dalam pelaporannya. Alat ini terbagi menjadi empat bagian utama dan pelengkapnya antara lain :

1. Kerangka sebagai tempat penopang system alat

2. Manometer (timbangan berat) sebagai pengukur beban

3. Pengait benda uji sebagai pencengkeram atau pemegang

4. Sistem penarik benda uji secara elektrik menggunakan motor listrik

5. Pelengkap yaitu cetakan untuk membuat benda uji tarik mortar

Ilustrasi rancangan ditunjukkan pada Gambar 2.3

\subsection{Proses pembuatan}

Pembuatan Prototip Rancangan Alat Uji Tarik Mortar Menggunakan Tenaga Penggerak Motor Listrik menggunakan sistem mekanis dan elektrik sederhana, yang dirancang dan dibuat seperti pada Gambar 3.3. a. Kerangka sebagai tempat penopang system alat, merupakan dudukan dari sistem alat itu sendiri, panjang, lebar dan tingginya disesuaikan dengan ukuran system alat yang ditopang diatasnya, sehingga kedudukanya stabil dan nyaman dioperasikan.

Adapun kerangka dan dudukan gear box ini terbuat dari bahan:

a) Baja holo $5 \times 5 \mathrm{~cm}$, pelat baja pelat tebal $7 \mathrm{~mm}$ dan $3 \mathrm{~mm}$

Rangka terbuat dari material ini yang dipotong-potong sesuai panjang yang diperlukan kemudian disambung dengan cara di las dan dibaut sesuai dengan jenis sambungan yang ditentukan. Dudukan gearbox dan motor listrik juga menggunakan baja holo $5 \times 5$ $\mathrm{cm}$.

b) Pelat tebal $1 \mathrm{~mm}$, digunakan sebagai penutup sistem penarik yang menggunakan gearbox dan motor listrik agar tetap terlindung serta keperluan estetika.

b. Manometer (timbangan) kapasitas 200 kg sebagai pengukur beban tarik, alat ini berkedudukan pada bagian atas kerangka, sedangkan bagian bawahnya dihubungkan dengan pengait atau sistem pencekam benda uji. Pengikatan manometer ini dengan sistem baut dan kait

c. Pengait atau pencekam benda uji, berfungsi untuk mengait benda uji sehingga benda uji dengan bentuk menyerupai angka 8 dan ukuran yang ditunjukkan pada gambar 2.1 tidak akan lepas ketika ditarik hingga putus.Pengait benda uji terdiri dari dua bagian yaitu bagian atas terhubung dengan manometer sedangkan bagian bawah terhubung dengan system penarik. Bagian alat ini terbuat dari baja dengan ketebalan $25 \mathrm{~mm}$ dibuat dan dibentuk dengan cara dibubut seperti yang ditunjukka pada gambar lampiran 1

d. Sistem penarik benda uji, bagian ini terdiri dari: 
a) Sistem penarik, ini terdiri dari gearbox sebagai transmisi gaya putaran menjadi gaya tarik. Gearbox ini merupakan set pabrikan yang dapat diperoleh di pasaran dengan perbandingan putaran input dan putaran outputnya sesuai kebutuhan

b) Motor listrik, bagian ini merupakan sumber tenaga penggerak setelah dihubungkan dengan arus listrik. Motor listrik ini akan menggerakkan gearbox pada bagian putaran inputnya yang dilengkapi transmisi gerigi dari motor listrik ke lengan putaran input.

Bagian sistem penarik ini terletak di bagian bawah rancangan alat dan terhubung dan memberikan gaya tarik terhadap pengait atau pencekam benda uji bagian bawah.

e. Cetakan benda uji tarik mortar sebagi kelengkapan untuk membuat benda uji yang berbentuk menyerupai angka delapan (Gambar 3.3). Cetakan dibuat dari pelat baja dengan tebal 2 $\mathrm{mm}$ dan lebar $20 \mathrm{~mm}$ sedangkan panjangnya sesuai dengan ukuran. Pembuatannya dengan cara dibengkokkan sehingga bentuk dan ukuran hasil cetakannya sesuai dengan gambar 2.1

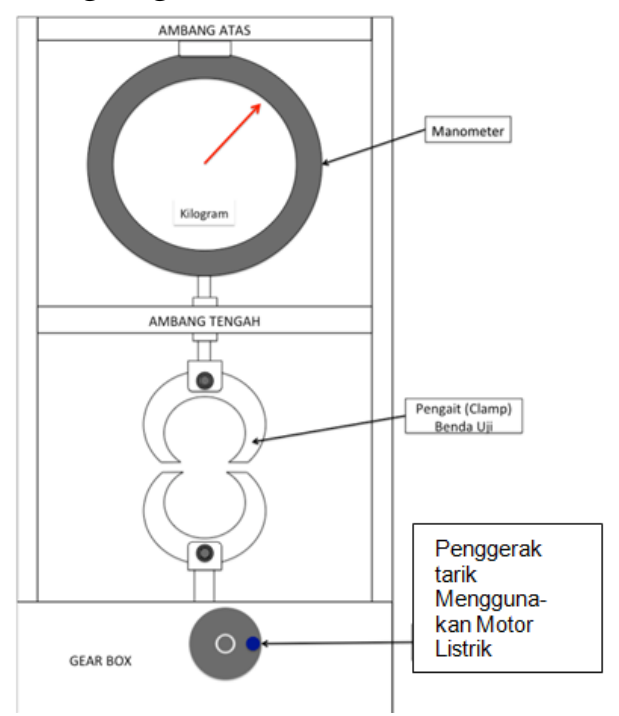

Gambar 2.3 Prototipe rancangan alat uji tarik mortar menggunakan tenaga penarik motor listrik

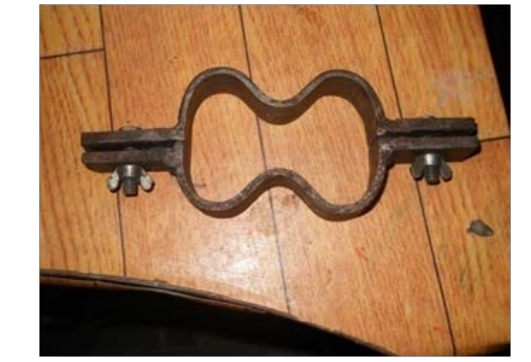

Gambar 2.4 Cetakan uji tarik mortar

\section{Prinsip Kerja alat}

Saat motor listrik dihidupkan maka akan menggerakan system penarik yaitu gearbox selanjutnya akan menarik bagian bawah pengait benda uji, dengan adanya benda uji tarik mortar antara pengait bagian bawah dengan bagian atas maka pengait bagian atas akan ketarik ke bawah. Pengait bagian atas berhubungan dengan manometer/ timbangan sehingga jarum manometer akan bergerak sebanding dengan bertambahnya gaya tarik oleh gearbox dan pada akhirnya benda uji tarik mortar akan putus karena tidak mampu menopang gaya tarik yang lebih besar jika dibandingkan dengan kemampuan kuat tarikbenda uji mortar. Besaran gaya tarik maksimum terbaca pada manometer ketika benda uji mortar putus.

\subsection{Pencapaian target}

Pencapaian target diperlihatkan dalam bagan fish bone pada Gambar 2.5

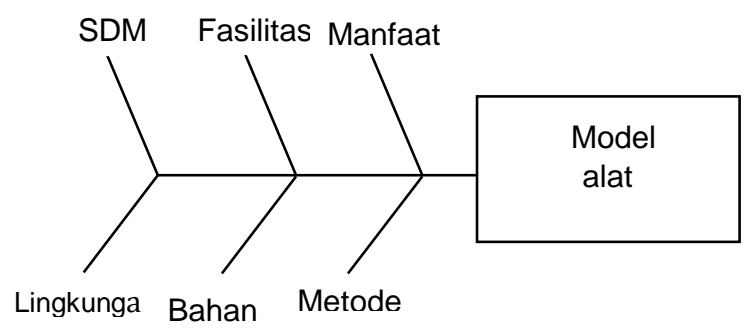

Gambar 2.5 Bagan fish bone pelaksanaan penelitian

Untuk mewujudkan target pencapaian terdapat beberapa faktor antara lain:

a. Sumber daya manusia (SDM), tim peneliti dengan latar belakang ilmu yang diampu dan pengalaman meneliti (track record) merasa mampu merancang dan mewujudkannya. Jika 
terjadi kendala di tengah perjalanan penelitian, di Lingkungan Politeknik Negeri Jakarta terdapat SDM di Jurusan Teknik Mesin dan Teknik Listrik.

b. Lingkungan, yang dimaksud adalah Laboratorium Uji Bahan Jurusan Teknik Sipil Politeknik Negeri Jakarta. Sejak tahun 1982 sampai sekarangLaboratorium Uji Bahan Jurusan Teknik Sipil Politeknik Negeri Jakarta belum memiliki Alat Uji Tarik Mortar, sehingga pengujian kuat tarik mortar tidak diajarkan kepada mahasiswa.

c. Fasilitas, merupakan sumber daya yang dapat digunakan untuk mewujudkan alat tersebut. Sumber daya disini berupa berbagai macam alat, perlengkapan penunjang dan ruangan yang berada di laboratorium konstruksi Jurusan Teknik Sipil PNJ

d. Bahan, merupakan bahan baku untuk mewujudkan alat tersebut. Bahan yang digunakan berupa bermacam-macam profil atau barang bentukan dari baja, bahan ini dapat diperoleh di JABODETABEK.

e. Manfaat, berdasarkan alasan belum adanya alat uji tarik mortar di Laboratorium Uji Bahan Jurusan Teknik Sipil Politeknik Negeri Jakarta, maka perlu dibuat alat tersebut. Alat ini dapat dimanfaatkan oleh dosen dan mahasiswa dalam proses pembelajaran dan penelitian lebih lanjut khususnya yang berhubungan dengan kuat tarik mortar.

f. Metode, merupakan pilihan yang mempunyai kelebihan yaitu handal, simple dan mudah dioperasikan untuk melakukan uji tarik mortar. Metode di sini juga mengandung unsur pilihan teknologi, sistem kerja tarik secara mekanis merupakan pilihan untuk memperoleh nilai beban tarik dengan cara pengoperasian yang sederhana.
Dengan pertimbangan faktor tersebut maka dirancang dan dibuatlah Alat Uji Tarik Mortar Menggunakan Tenaga Penggerak Motor Listrik. Alat yang akan dibuat ini diharapkan dapat berfungsi sebagaimana mestinya maka ini merupakan model atau Prototipe. Pencapaian target adalah terwujudnya PrototipAlat Uji Tarik Mortar Menggunakan Tenaga Penggerak Motor Listrik

Hasil uji kuat tarik mortar menggunakan alat hasil rancangan ini kemudian dibandingkan dengan hasil uji kuat tarik mortar menggunakan alat standar, selanjutnya hasil perbandingannya diamati apakah mendekati dengan hasil uji menggunakan alat standar atau tidak. Jika hasilnya mendekati berarti alat hasil rancangan tersebut dapat direkomendasikan sebagai alat alternatif uji kuat tarik mortar

\subsection{Bahan dan alat}

Bahan-bahan yang yang digunakan dalam penelitian ini antara lain :

1. Bahan Untuk Membuat Prototipe alat uji tarik dan Cetakan

- Baja holo segi empat 50x50 mm

- Besi siku ukuran 40 mm x 40 mm x 5 mm

- Pelat baja tebal $25 \mathrm{~mm}$

- Pelat baja tebal $3 \mathrm{~mm}$

- Pelat baja tebal $1 \mathrm{~mm}$

- Mur baut ukuran 10 mm

- Motor Listrik berikut roda gigi

- Manometer kapasitas 200 kg

- Mata gerinda

- Abrasive metal

- Elektroda

- Gas oksigen

- Gas asitelin

- Kawal las

- Cat

- Thiner

2. Bahan untuk membuat benda uji mortar

- Pasir (agregat halus)

- Semen 
- Air

3. Alat Yang Digunakan

Alat-alat yang digunakan adalah meliputi :

- Mesin gergaji besi

- Mesin bor

- Mesin las listrik

- Mesin las gas

- Mesin gerinda

- Spray gun

- Kompresor angin

- Mesin pengaduk mortar

- Dan alat bantu lainya

Peralatan yang digunakan adalah peralatan yang ada di Laboratorium Konstruksi dan Laboratorium Bahan Bangunan Jurusan Teknik Sipil Politeknik Negeri Jakarta

\section{HASIL DAN PEMBAHASAN}

\subsection{Proses Konstruksi}

Pada proses ini ada 3 bagian utama yang akan dilaksanakan proses pembuatannya yaitu proses pembuatan dudukan, sistem penggiling dan sistem penarik

a. Rangka manometer dan pengait

Rangka manometer dan pengait merupakan bagian alat yang berfungsi sebagai dudukan atau tumpuan manometer dan pengait benda uji. Bahan utama pada bagian ini dari baja baja holo segi empat 50x50 mm dipotong sesuai panjang setiap bagian dan dirangkai menggunakan pelat baja $8 \mathrm{~mm}$ dan $3 \mathrm{~mm}$ menggunakan las serta baut diameter $10 \mathrm{~mm}$

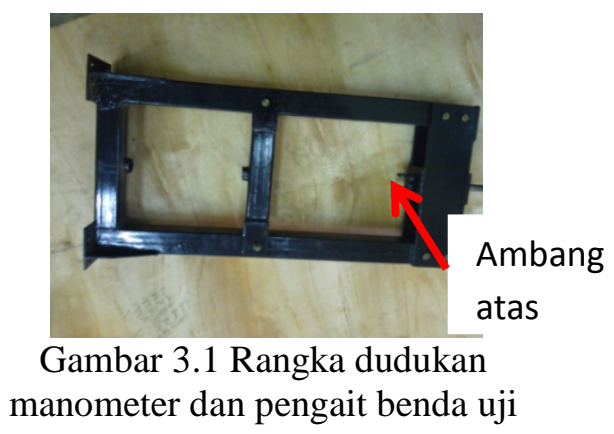

Adapun komponen dari dudukan ini adalah:

1) Tiang kanan dan kiri
Dari bahan baja holo segi empat 50x50 mm dirangkai dengan ambang menggunakan las dan baut

2) Ambang atas, tengah dan bawah Manometer terletak diantara dua tiang dan ambang atas dan ambang tengah.

b. Manometer atau timbangan

Timbangan gantug dapat diperoleh dipasaran, dipilih kapasitas 200 kilogram

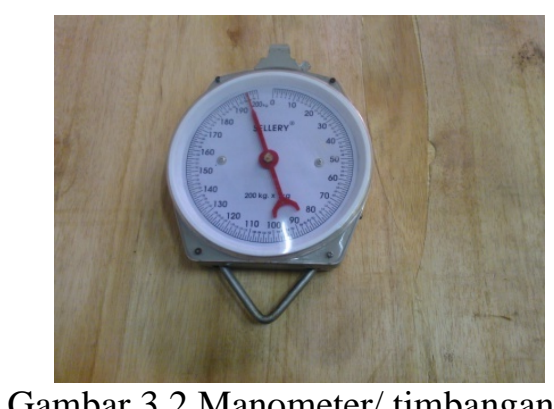

c. Pengait atau Klem

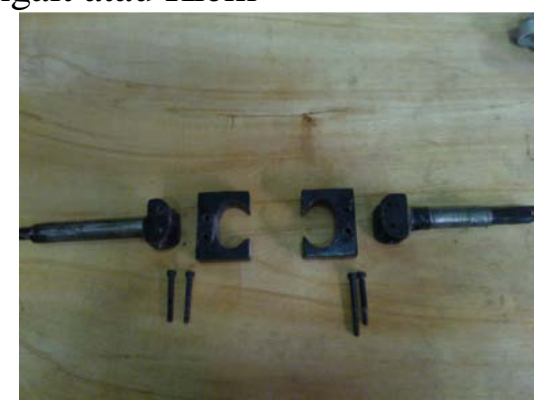

Gambar 3.3 Pengait benda uji

Pengait dibentuk dari baja tebal 25 $\mathrm{mm}$ dan lengannya dari baja berdiameter $20 \mathrm{~mm}$

d. Rangka dan dudukan sistem penggerak

Bagian ini menggunakan bahan baja holo 50x50 mm dibentuk bangun kubus, bagian sambungan menggunakan las. Guna tujuan keamanan dan estetika maka digunakan baja pelat tebal $1 \mathrm{~mm}$ sebagai penutup sekelilingnya, di bagian depan dan belakang penutupnya dirancang bisa dibuka tutup mengunakan baut $6 \mathrm{~mm}$ namun pada samping kanan, kiri, atas dan 
bawah dibuat permanen dengancara dikas. Bagian dududkan juga menggunakan baja holo 50x50 mm sperti yang ditunjukkan pada Gambar 5.5

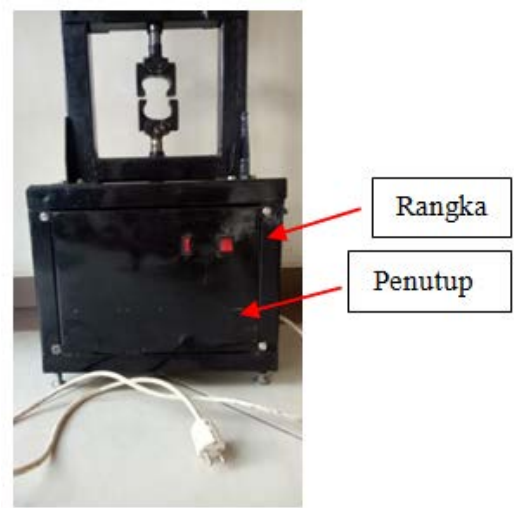

Gambar 3.4 Rangka dan dudukan sistem penggerak

e. Sistem penggerak

Sistem penggerak merupakan bagian sumber tenaga untuk menarik bagian bawah lengan pengait benda uji yang terdiri dari 2 bagian yaitu:

1) Gearbox

Gearbox adalah roda gigi yang merupakan satu kesatuan dengan kotak atau box dan lengan tranmisi untuk sumber tenaga putaran (input) dan lengan gaya (output) untuk menarik bagian bawah lengan pengait benda uji. Kedua tuas ini sistem geraknya berupa putaran dimana putaran pada tuas input menghasilkan putaran yang lebih lambat pada tuas output. Set gearbox ini dapat diperoleh dipasaran.

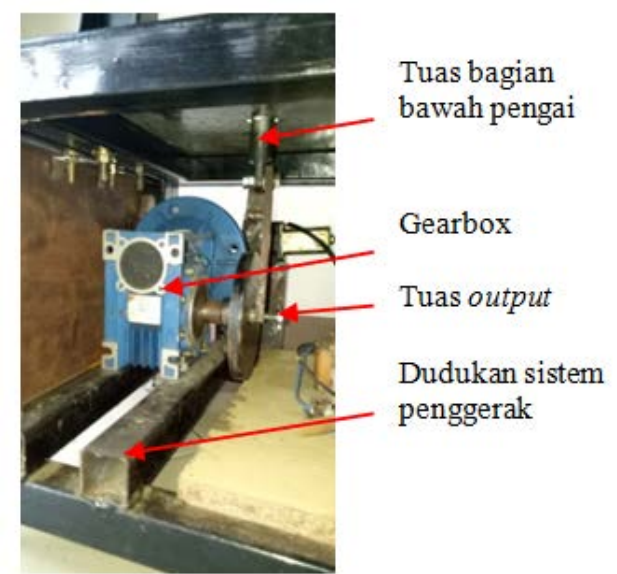

Gambar 3.5 Dudukan sistem penggerak dan gear box f. Motor listrik

Motor Listrik merupakan sumber tenaga penggerak yang memutar tuas input gearbox melalui tranmisi roda gigi. Motor listrik penggerak yang digunakan jenis motor listrik arus DC

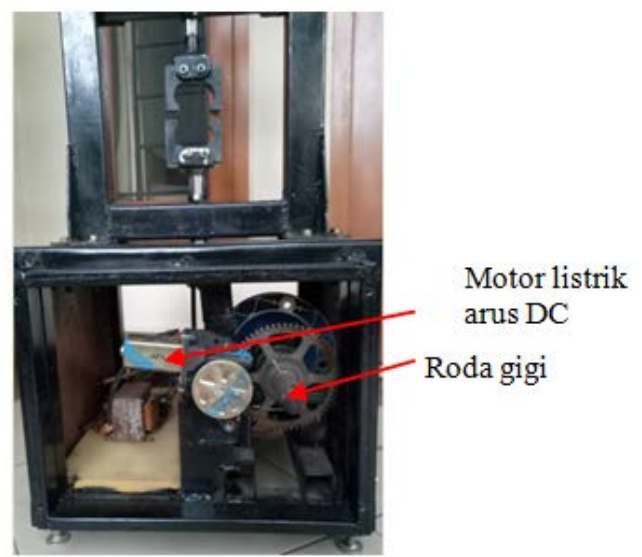

Gambar 3.6 Sistem penggerak menggunakan tenaga listrik

\subsection{Pengujian Model}

Perancangan dan pembuatan alat uji tarik menggunakan tenaga motor listrik dengan sistem coba-coba telah selesai, guna memastikan dapat berfungsi atau tidaknya maka dilakukan uji pengoperasian. Pengujian pengoperasian dengan cara membuat benda uji tarik mortar sesuai standard yang sudah cukup umur kemudian dilakukan uji tarik menggunakan alat hasil rancangan yang dimaksud.

a) Pelaksanaan pengoperasian

Disediakan benda uji mortar campuran 1 semen : 5 pasir yang sudah cukup umur.

Berikut langkah pelaksanaannya:

1. Sebelumnya telah membuat benda uji tarik mortar dengan perhitungan ketika akan dilakukan uji coba alat benda uji tersebut sudah cukup umur (minimal 28 hari)

2. Dipersiapkan alat yang telah selesai dibuat.

3. Benda uji ditempatkan pada pengait dan dipastikan jarum manometer menunjuk angka 0 (nol atau kosong) dan dipastikan pula benda uji tidak terlepas dari 


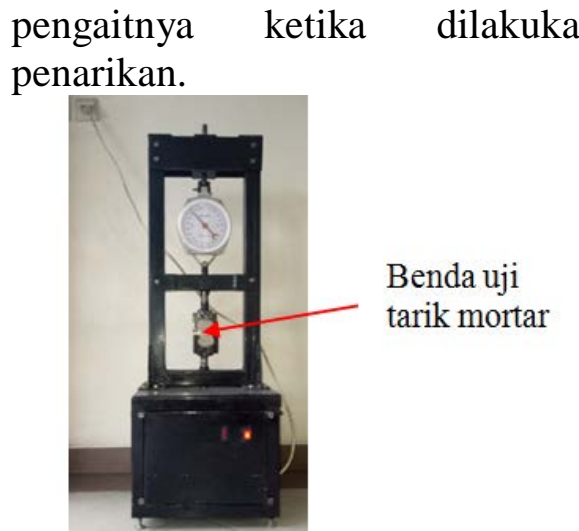

Gambar 3.7 Penyetelan benda uji

4. Sediakan alat tulis yang diperlukan

5. Hubungkan alat tersebut dengan sumber arus listrik

6. Nyalakan tombol On-Off pada posisi on sehingga motor penggerak akan beerputar menggerakkan tuas input gearbox dan tuas pengait bagian bawah akan tertarik ke bawah.

7. Amati pergerakan jarum manometer dan catat nilai angka tertinggi ketika benda uji mortar putus.

8. Lakukan langkah 3 sampai dengan 7 untuk benda uji berikutnya

9. Hitung kuat tarik setiap benda uji.

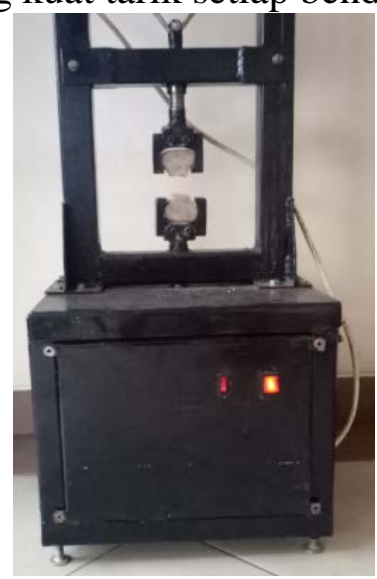

Gambar 3.8 Benda uji putus

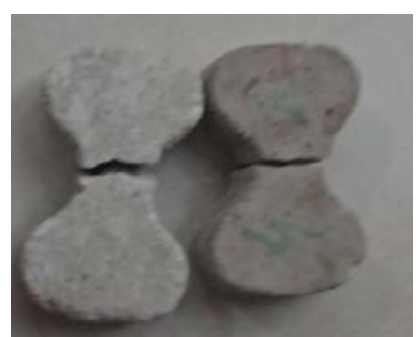

Gambar 3.9 Benda uji tarik mortar yang telah putus
Kendala - kendala yang terjadi selama uji coba:

Dari hasil pengamatan selama alat ini dioperasikan timbul kendala - kendala sebagai berikut:

1. Pergerakan tarik terlalu cepat.

2. Pengamatan jarum manometer ketika mencapai beban maksimum harus cermat karena setelah benda uji terputus jarum kembali ke posisi 0

3. Ukuran benda uji dengan ukuran kait kurang sinkron sehingga ketika dilakukan penempatan benda uji agak kesulitan.

\subsection{Pengujian Hasil}

Pengujian hasil meluruskan baja tulangan merupakan rangkaian pengujian pengoperasian alat dimana selain mengamati sistem kerja alat juga seberapa jauh baja tulangan bisa diluruskan.

a. Bahan

Bahan yang diuji berupa mortar yang sudah dicetak menggunakan cetakan berumur minimum 28 hari. Bahan baku pasir diperoleh di sekitar toko material di Depok dan semen menggunakan semen tipe PCC

b. Proses pengujian

Proses meluruskan merujuk atau sesuai dengan 5.2.a pelaksanaan pengoperasian

c. Pengukuran

Pengukuran dilakukan dengan mengamati beban maksimum setiap benda uji

d. Hasil dan pembahasan pengukuran penyimpangan kelurusan

Dari pengukuran penyimpangan kelurusan batang baja tulangan maka hasilnya ditunjukkan pada Tabel 3.1 
Tabel 3.1. Hasil uji kuat tarik mortar

\begin{tabular}{lrrrrr}
\hline & & Umur & Beban & \multicolumn{2}{c}{ Kuat Tekan } \\
No & Kode & Maks. & \multicolumn{2}{c}{$\left(\mathrm{kg} / \mathrm{cm}^{2}\right)$} \\
& & (hari) & $(\mathrm{kg})$ & Satuan & Rata-rata \\
\hline 1 & 512 & 50 & 100,0 & 20,756 & \\
2 & 512 & 50 & 90,00 & 16,520 & \\
3 & 512 & 50 & 130,0 & 20,425 & 18,473 \\
4 & 512 & 50 & 90,0 & 16,190 & \\
\hline 1 & 812 & 47 & 90,0 & 15,866 & \\
2 & 812 & 47 & 140,0 & 21,509 & \\
3 & 812 & 47 & 140,0 & 25,909 & 22,703 \\
4 & 812 & 47 & 160,0 & 27,528 & \\
\hline 1 & 912 & 46 & 125,0 & 24,082 & \\
2 & 912 & 46 & 140,0 & 24,828 & \\
3 & 912 & 46 & 120,0 & 25,856 & 25,476 \\
4 & 912 & 46 & 160,0 & 27,137 & \\
\hline
\end{tabular}

Merujuk hasil pengujian kuat tarik mortar keras pada Tabel 5.1 diperoleh hasil, bahwa alat dapat digunakan untuk melakukan pengujian kuat tarik mortar keras dengan ukuran benda uji sesuai standar ASTM C307. Mortar dengan perbandingan 1 semen : 5 pasir, ada 3 variasi umur yaitu 50; 49 dan 48 hari dari masing-masing variasi berjumlah 4 benda uji.

Hasil kuat tarik rata-rata menunjukkan semakin muda umur mortar semakin tinggi kuat tariknya, hal ini dikarenakan pembuatan dilakukan dilakukan sebanyak 3 kali berbeda hari serta sebelumnya tidak dilakukan uji fisis terhadap bahan agregat halusnya termasuk pengujian mortar basah. Terlepas dari hasil akhir kuat tarik yang dirasa aneh namun yang lebih penting adalah bahwa alat tersebut dapat diporeasikan sebagimana mestinya sesuai dengan fungsi yang dirancang walaupun terjadi kekurangan-kekurangan.

\section{KESIMPULAN}

Dari hasil pelaksanaan pembuatan alat uji tarik mortar menggunakan tenaga penggerak motor listrik dan pengujian pengoperasian maupun pengujian hasil, maka dapat ditarik kesimpulan sebagai berikut:

1. Proses pembuatan alat dengan sistem coba-coba atau eksperimen membutuhkan perhatian yang serius sertan setiap bagian alat sudah dibuat perlu uji coba lebih dahulu.

2. Rancangan alat berupa prototipe alat uji kuat tarik mortar menggunakan tenaga penggerak motor listrik dapat berfungsi sebagaimana mestinya.

3. Hasil rata-rata uji tari mortar yang menunjukkan semakin muda umur mortar semakin tinggi kuat tariknya tidak ada kaitannya dengan sistem kerja alat yang bersangkutan.

4. Tingkat kesempurnaan alat sesuai yang diharapkan harus melalui proses yang sederhana meningkat ke perbaikan-perbaikan sehingga diperoleh alat yang dapat berfungsi sebagaimana mestinya.

\section{DAFTAR PUSTAKA}

[1] ASTM C 307-99 Standard Test Method forTensile Strength of Chemical-Resistant Mortar, Grouts, and Monolithic Surfacings

[2] Mualif. 2012. "Pembuatan Alat Uji Tarik Material”. Program Mahasiswa Ekstensi Fakultas Matematika dan Ilmu Pengetahuan Alam Universitas

Indonesia

[3] Riyadi dan Sarito, Sudardja, Setiyadi. 2015. "Perancangan Alata Uji Tarik Mortar”. Politeknik Negeri Jakarta

[4] Sufiandi. 2007. "Perancangan dan Pengembangan Alat Uji Tarik/Tekan Portabel Dengan Data Akuisisi”. Skripsi Teknik Mesin Universitas Indonesia

[5] Tjokrodimulyo. 2007. "Teknologi Beton, Teknik Sipil dan Lingkungan”. Universitas Gadjah Mada Yogyakarta. 
Sarito dkk, Perancangan Alat Uji Tarik Mortar... 